\title{
ANDRES TRAPIELLO, EL QUIJOTE Y LAS VIDAS DESPUÉS DE LA MUERTE DE ALONSO QUIJANO
}

\author{
BLAS SÁNCHEZ DueÑas \\ Universidad de Córdoba
}

\section{Trapiello ante SU OBRA}

Desde la publicación de la primera parte de El ingenioso hidalgo don Quijote de la Mancha en enero de 1605, han sido muchos los escritores que, de una forma u otra, han pretendido aprovecharse del texto y de los personajes creados por Miguel de Cervantes para continuar sus hazañas, completar sus vidas o desplegar las escenas y protagonistas quijotescos hacia otras latitudes como ha sido recogido en trabajos como los de E. Cotarelo hasta los inicios del siglo XX o los de D. Villanueva ${ }^{1}$.

\footnotetext{
1 E. Cotarelo y Mori, "Otro imitador de Cervantes en el siglo XVIII" y "Las imitaciones castellanas del Quijote", en Estudios de historia literaria de España, I, Madrid, 1901; D. Villanueva, "El Quijote desde la novela actual", en I. Suárez Andrés et al. (eds.), Huellas del Quijote en la narrativa española contemporánea, Actas de las Jornadas Hispánicas de Neuchâtel, 25-25 de noviembre de 1995, Universidad de Neuchâtel, 1996, pp. 13-31. La bibliografía sobre las continuaciones del Quijote en diferentes momentos de la historia
} 
En las vísperas de 2005, annus mirabilis al conmemorarse el cuarto centenario de la publicación de la magna obra cervantina, Andrés Trapiello publica la novela Al morir don Quijote $^{2}$ motivada por el afecto y la admiración que el escritor leonés profesa al Quijote y a su autor ${ }^{3}$ y con la intención de indagar en las vidas de los deuteragonistas quijotescos, descubrir sus sentimientos, sus anhelos, sus desamores y sus preocupaciones y dar voz a unos personajes que quedaban sin historia al morir don Quijote, eje centrípeto de sus vidas.

Según ha declarado el escritor leonés, los personajes del Quijote lo enamoraron de tal modo que, tras la muerte del héroe, la orfandad de los que lo rodeaban avivó el interés por saber qué sería de sus vidas después de Alonso Quijano por lo que, ante la imposibilidad de que alguien se las contara, él mismo decidió prolongarlas y contarlas de un modo natural a favor de Cervantes y a favor de cada uno de ellos 4 .

Para A. Trapiello: «Una novela de estas características sólo se escribe desde el amor a Cervantes y a sus personajes» ${ }^{5}$. Este motivo, unido a su deseo de conocimiento y de fabulación sobre lo que pudo ser de las vidas huérfanas de los protagonistas

literaria es amplia. Entre otros pueden consultarse los trabajos de H. Mancing, "Jacinto María Delgado and Cide Hamete Benengeli: A Semi-Classic Recovered and A Bibliographical Labyrinth Explored", Bulletin of the Cervantes Society of America 7.1., 1987, pp. 13-43. Véase también E. Sánchez Moreno, Los otros quijotes, en www.juntadeandalucia.es/averroes/ 23002413/forodepapel/7/forodepapel72.pdf; P. Álvarez de Miranda, "Sobre el 'quijotismo' dieciochesco y las imitaciones reaccionarias del Quijote en el primer siglo XIX", Dieciocho, 27.12004 (Special Issue in Honor of René Andioc), pp. 31-46; http:// wapedia.mobi/es/Continuaciones_del_Quijote; O. Barrero Pérez, "Imitadores y continuadores del Quijote en la novela española del siglo XVIII", Anales Cervantinos, 24 (1986), pp. 103-121.

2 Todas las citas de este trabajo se anotarán a partir de la edición A. Trapiello, Al morir don Quijote, Barcelona, Ediciones Destino, 2004.

3 Andrés Trapiello, en Nota a Las tradiciones (1979-1988) (Granada, La Veleta), volumen recopilatorio de su poesía completa en 1991, confesaba lo que supone la lectura y la tradición literaria en su obra: «No sé cuánto pueda tener de propia mi voz, pero sé lo mucho que le debe a otras voces e, incluso, a otros ecos», cito por Rosendo Tello, "El punto oscilante en Las tradiciones de A. Trapiello", Poesía en el campus. Revista de poesía, $\mathrm{n}^{\circ}$ 37, 1996-1997, p. 10. La tradición literaria forma parte indisoluble de su concepción literaria y de su práctica estética. Entre otras muchas fuentes y lecturas, directamente relacionado con el cervantismo y el quijotismo, recuérdese que en 1993 publicó Las vidas de Miguel de Cervantes con la pretensión de desvelar algunos de los enigmas que envuelven la vida de Cervantes mediante una biografía novelada y que en 2005 publicó ... y Cervantes con interesantes análisis sobre el tratamiento del héroe y de su autor según la historia crítica. Del mismo modo, repárese en que en otras novelas del leonés aparecen elementos típicamente cervantinos y quijotescos como el recurso a la utilización de un manuscrito encontrado como motor de la acción en Días y noches (2000) o como la creación de personajes secundarios de ascendencia cervantina como el barbero o el cura o la necesidad que tiene el género policíaco de encontrar un ejecutor, cómo Cervantes hizo con la novela caballeresca tal y como se forja en Los amigos del crimen perfecto (2003).

${ }^{4}$ A. Intxausti, "Andrés Trapiello se apropia de los personajes del 'Quijote' e inventa sus vidas", El País, 14 de octubre 2004. Consulta digital en http://www.elpais.com/articulo/cultura/Andres/Trapiello/ apropia/personajes/Quijote/inventa/vidas/elpepicul/20041014elpepicul_7/Tes [Última consulta septiembre de 2011]

${ }^{5}$ A. Castilla, "Trapiello gana el Fundación Lara con "Al morir don Quijote", El País, 8 de abril de 2005, p. 39. 
quijotescos muerto don Quijote, lo llevan a reinventar las vidas de algunos de los personajes de Cervantes tras la ausencia de aquél por lo que este libro supone un viaje hacia el conocimiento y el entretenimiento donde el autor busca compañeros de destino en el propio universo cervantino para circundar y bucear en sus vidas, saber más de ellos, de sus hazañas, de sus reacciones ante la muerte del héroe y de su visión de aquél y de ellos mismos.

\section{ESTRUCTURA Y TIEMPO DE LA NARRACIÓN}

Con un título como Al morir don Quijote es significativo que en la cubierta del libro no aparezca ningún motivo propiamente quijotesco o cervantino, sino que dicha cubierta original ${ }^{6}$ aparezca presidida por la imagen de una joven lozana que mira al frente, con la cara apoyada sobre su mano derecha en actitud de serenidad y tranquilidad. Sobre fondo blanco roto, la ilustración de la joven con sonrisa traviesa y apicarada pero serena, recodada sobre una ventana y mirando con ternura y placidez desde dentro al desconocido lector, junto las menciones del título y del autor en un juego de blanco y negro, está extraída de un cuadro de Bartolomé Esteban Murillo (Sevilla, 1617-1682) titulado Dos mujeres en la ventana, (Washington, National Gallery of Art) - también conocido como Gallegas en la ventana-. Es un retrato incompleto ya que, si se observa el cuadro de Murillo completo, éste ofrece a dos mujeres: la lozana que encabeza el libro de Trapiello y otra mujer de mayor edad que esconde parte de su faz tras un velo y que apenas si asoma parte de su rostro y su mano izquierda tras el postigo de una ventana.

A pesar de no contar con ningún icono ilustrativo o de sustanciales reminiscencias del Quijote o con algún otro motivo cervantino, la ilustración de la cubierta encuadra al lector en una época: la de Murillo, casi coetánea con la de Cervantes, y ofrece una imagen: la de una moza cuyos ojos y serenidad atraen al lector, invita a la lectura por su belleza natural, su juventud, su leve sonrisa y su frescura y, a la vez, parece desvelar figurativamente la imagen de un personaje protagonista de la novela si nos atenemos a la descripción que en cierto pasaje del capítulo veintisiete se hace de Antonia, sobrina de don Quijote, que evoca o recuerda esa desconocida lozana que nos mira desde la cubierta: «Vestía Antonia un corpiño que dibujaba con infinita suavidad dos pechos del tamaño de aquella manzanas. Toda la gracia de sus diecinueve años se le salía por el escote como un ramo de rosas, y el fulgor de sus ojos la hacía resplandecer de tal modo que no era fácil mantenerse a su lado sin deslumbrarse» ${ }^{7}$. Y es que, a pesar de la

${ }_{6}$ Con posterioridad se ha realizado otra edición donde la imagen central ocupa toda la cubierta y aparece otra disposición gráfica del título y nombre del autor.

7 A. Trapiello, op. cit., p. 295. 
muerte de don Quijote, para el escritor leonés la vida de los personajes que lo rodearon continúa.

Estas vidas, obras y avatares, que es lo que Andrés Trapiello quiere ofrecer al lector en esta novela para tratar de llevar hacia el texto cervantino clásico a los lectores contemporáneos. Trapiello trataba de ilusionar al lector contemporáneo mediante las intertextualidades y palimpsestos tendidos hacia la obra cervantina con la intención de que, cuando el lector del siglo XXI leyera las aventuras de los coadyuvantes quijotescos, se interesara por la fuente literaria que los vio nacer y se abrieran cauces hacia la lectura del texto de 1605.

Estructuralmente, Al morir don Quijote se divide en 37 capítulos de diferente extensión, variando desde las cuatro páginas que componen los capítulos séptimo y vigésimo cuarto a las veintidós sobre las que se asienta el capítulo veinte.

La novela adecua su estructura narrativa al clásico naturalis temporum ordus, es decir, la historia relatada ofrece una temporalización más o menos lineal desarrollada a lo largo de poco más de tres meses, período que dista desde la madrugada de un caluroso día de octubre de 1614, fecha en la que muere don Quijote, hasta los primeros meses de 1615 en los que los principales protagonistas de la novela de Trapiello - a saber, Sansón Carrasco, Sancho Panza, Antonia, sobrina de don Quijote, y Quiteria, el ama de la casa - toman la postrera resolución de abandonar el innominado pueblo del héroe cervantino y toda aquella vida que les rodea y deciden embarcarse en una nueva vida simbolizada en todo lo que pueda ofrecerles el Nuevo Mundo comenzando por la consecución de la libertad que los personajes alcanzan al dejar atrás el innominado pueblo que vio encumbrar sus hazañas.

Para completar y esclarecer con mayor rigor lo dicho sobre la línea y período temporal de la secuencia narrativa relatada no pueden olvidarse dos cuestiones de interés. En primer lugar no hay una adecuación entre la trayectoria cronológica de la historia de ficción y la historia real que sustentan los hechos de los personajes. Trapiello sitúa la acción en octubre de 1614 en los últimos instantes de vida de don Quijote y finaliza su novela apenas tres meses después de iniciarse la acción. Sin embargo, el autor se permite ciertas licencias temporales como la de situar la muerte de Cervantes el 23 de noviembre, cuando, como es conocido, éste muere el veintidós de abril de 1616, siendo enterrado un día después, o la de que los personajes puedan regocijarse con la lectura de la segunda parte del Quijote en ese momento cuando el libro es aprobado en 1615 con fecha 5 de noviembre por Gutiérrez de Cetina saliendo posteriormente de las prensas de Juan de la Cuesta ${ }^{8}$.

8 M. de Riquer, Para leer a Cervantes, Barcelona, Acantilado, 2003, pp. 92-94. 
En segundo lugar, como suele ocurrir en las modalizaciones del tiempo narrativo, en el interior del texto los hechos narrados ofrecerán numerosas analepsis con respecto al eje narrativo temporal en escenas donde la temporalización es retrospectiva. El narrador omnisciente vuelve su mirada al pasado de los personajes y recuerda algunos hechos relativos a sus vidas o hazañas. Los propios protagonistas novelescos retroceden en el tiempo para recordar sus aventuras al lado del héroe cervantino siguiendo algunos de los episodios o escenas conocidas de la obra de Cervantes o al hablar sobre lo que era su existencia en vida del hidalgo manchego. Aventuras y analepsis que siguen el texto cervantino o que vienen emanadas de la imaginación de Trapiello al fabular sobre lo que fueron las vidas de estos personajes o lo que conversaban, hacían o pensaban al vivir junto a don Quijote.

Igualmente, como recurso narrativo que afecta a la temporalidad del orden discursivo de la novela, puede señalarse que, sobre todo en los primeros capítulos, su desarrollo narrativo se sustenta y realiza mediante la técnica de la simultaneidad temporal gracias a la cual el narrador ofrece los movimientos, acciones o pensamientos delos personajes coincidiendo en un mismo instante temporal. Enlos primeros capítulos, perfectamente ejemplificado en el sexto, las escenas se superponen coincidiendo en el tiempo con la finalidad de presentar simultáneamente a los personajes que protagonizarán la novela de Trapiello, describir sus actos en el momento de la muerte de don Quijote y establecer las relaciones, pensamientos, sentimientos y recuerdos que, en cada uno, provoca la desaparición del protagonista cervantino focalizando Trapiello su óptica desde Antonia a Quiteria pasando por Sansón Carrasco o Sancho Panza y su familia.

En cuanto a los hechos relatados sobre los que se sustenta la urdimbre narrativa de esta obra, el relato parece estructurarse en torno a tres partes que van a venir caracterizadas por la narración del proceso vital abarcado desde que los protagonistas que el caballero castellano deja huérfanos inician la búsqueda personal de asideros para afianzar sus vidas y luchan por la consecución de los nuevos ideales y fines que, en ellos, emergen o se despiertan tras la muerte de don Quijote, hasta que éstos alcancen a discernir lo que realmente quieren hacer con sus vidas y nuevas andanzas y la postrera determinación de abandonar lo conocido e iniciar una nueva vida embarcándose hacia el Nuevo Mundo, símbolo de libertad para todos ellos.

De acuerdo con este planteamiento, la novela responde a un esquema tradicional. Una primera unidad narrativa abarca los doce primeros capítulos. Con una dilación temporal que tan sólo refleja los aconteceres de un solo día, el correspondiente a la muerte y entierro de don Quijote y, en consonancia con algunos de los hechos y registros temporales descritos por Cervantes en la segunda parte de su obra, el 
principal nudo de acción de esta parte se centra en la relación de la muerte del hidalgo, su entierro, las reminiscencias que las hazañas, dichos y hechos de aquél despiertan en cada actante, y la presentación de los personajes, deteniéndose el autor en ricas descripciones de los protagonistas novelescos y del tiempo atmosférico, así como en interesantes evocaciones acerca de lo que el Caballero de la Triste Figura simboliza para cada protagonista y los recuerdos que todos ellos guardan de él.

A este respecto, véanse como ejemplo comparativo los matices del pensamiento de Quiteria, el ama de Alonso Quijano, en confrontación con los del cura don Pedro. Trapiello, al comenzar el capítulo sexto, advierte: «la muerte de don Quijote no afectó, como es natural, a todos de la misma manera ${ }^{9}$, lanzándose con prontitud a relatar lo que pasa por la cabeza de Quiteria, la de Sansón Carrasco o la de Antonia. Léase como botón de muestra lo relatado sobre Quiteria:

Para el ama Quiteria fue un verdadero cataclismo. Después de aquellas primeras lágrimas, mientras abrazó a Antonia, no se volvió a verla llorar en todo el día, y de ello podría sacarse una impresión equivocada. [...].

Ah, si la hubiera visto alguien dejando aquellos dos besos tan amorosos e inopinados en la cabeza de don Quijote. ¿Qué hubieran dicho de aquellas confianzas?

- ¿Cómo se ha dejado morir vuesa merced? Y ahora, ¿qué será de mi vida?

Y siguió haciéndole al muerto otras mil preguntas, todas a media voz, no porque pensara que iba a respondérselas, sino como si quisiera dormirle, igual que cuando se sigue contando un cuento a un niño que hace ya un buen rato se ha hundido en el insondable mundo de la almohada y los sueños. ${ }^{10}$

En contraposición, se ofrece el fragmento expuesto sobre los sentimientos que se acunan en el cura tras la muerte del héroe:

El cura, compungido como la mayoría por aquella mala noticia, había llegado a la rectoral y a medida que pasaban los minutos se entristecía más y más. Sabía que había muerto cristianamente y confesado y que había sido ungido por el santo óleo, pero no le bastaba. No se resignaba a que hubiese muerto. No era sólo uno de sus mejores amigos, sino de los más antiguos, y con él había jugado cuando Alonso era un niño aún, recién llegado don Pedro al pueblo con las órdenes apenas estrenadas, y con él había cazado con visco pájaros, y leído con él, a menudo en los mismos ejemplares, las primeras novelas. Y de pronto, con los ojos bañados en lágrimas, en la soledad de su casa, y sin que nadie le viese rezón por el alma de su amigo más de dos horas seguidas, y le parecía que rezando por su alma, lo hacía por la suya propia, y empezó a creer que el siguiente en seguirle a la tumba sería él mismo. ${ }^{11}$

Podría disgregarse una segunda unidad estructural cuyo eje vertebral es la revelación de lo que cada personaje pretende hacer tras la desaparición del protagonista

\footnotetext{
9 A. Trapiello, op. cit., p. 46.

10 Ibídem, p. 46-47.

11 Ibídem, p. 60.
} 
cervantino, es decir, el inicio de la búsqueda personal e identitaria, de lo que pretenden hacer con sus vidas ya al margen y la mediada distancia con Alonso Quijano.

Los deuteragonistas quijotescos, convertidos por Trapiello en figuras principales de su libro, se aprestan a reorganizar sus vidas y a emprender nuevos rumbos para sus historias vitales. De acuerdo con ello, poco a poco, cada uno va a ir desenredando su porvenir y va a ir descubriendo las nuevas metas hacia las que quieren dirigir sus vidas una vez desaparecido el eje central de sus vidas y la figura que los vinculaba y sobre la que giraba buena parte de su ser, de su existencia y de su acción. Aproximadamente, ese camino desde la orfandad al descubrimiento de la nueva vida se desarrolla desde el capítulo trece hasta la entrada en escena de los duques que cedieron a Sancho el gobierno de la ínsula Barataria en el capítulo treinta y uno.

Estos capítulos conforman la columna vertebral de la novela de Trapiello y responden a uno de los propósitos principales del autor al decidirse a continuar las vidas y hazañas de los protagonistas quijotescos. En ellos se asiste a la narración de distintos acontecimientos y peripecias de los protagonistas de Trapiello hasta que cada uno vaya alcanzando los deseos proyectados.

Finalmente, los últimos seis capítulos encaminan la trama hacia un desenlace tradicional donde se resuelven todos los conflictos planteados; se llevan a cabo los escarmientos de los pérfidos antagonistas novelescos; se obtienen las metas deseadas; $\mathrm{y}$, en ellos, los personajes, después del incesante proceso de búsqueda, identificación, resolución y determinación en lo que atañe a sus vidas, inician triunfantes un nuevo camino que es el encontrado y anhelado por cada uno de ellos que, en este caso, es el mismo para los cuatro personajes principales, el ya mencionado paso a América en búsqueda de nuevas horizontes y de esperanzadas expectativas para sus vidas.

\section{Claves compositivas}

Algunas de las claves compositivas y de los factores dominantes y determinantes de la novela, los ha ido desgranando el propio autor a lo largo de numerosas entrevistas y declaraciones realizadas al hilo del proceso de promoción de la obra. En primer lugar, como se ha colegido con anterioridad, con el libro, Trapiello pretendía rendir homenaje a Cervantes y a don Quijote además de animar e incentivar la lectura del Quijote en el IV centenario de la publicación de su primera parte. Por otra parte, estaba muy interesado en indagar y novelar sobre lo que la vida podía deparar a los deuteragonistas quijotescos al margen del propio héroe literario: «Al morir don Quijote es una novela en la que los personajes que rodearon al Caballero de la Triste Figura 
reviven para darse cuenta de que «el mundo será mejor cuantos más quijotes haya» ${ }^{12}$ y de que «la literatura y la vida son una tarea común». ${ }^{13}$ Pero, por encima de cualquier declaración, el propósito que anima al escritor se reproduce en el propio interior de la novela. Léase el amplio fragmento que se transcribe a continuación porque, en él, a modo de guión, el omnisciente narrador, -Andrés Trapiello-, que manejará desde la voz dominante de la omnisciencia autorial los hilos de estas figuras de ficción, anticipa y presenta buena parte de los motivos que retomará para continuar sus historias, anunciando en las primeras páginas de la novela lo que le atrae de la obra cervantina así como la sed de conocimiento que se despierta en su imaginación tras leer la novela de Cervantes:

Al morir don Quijote, los más ingenuos pensaron que se cerraba su historia, de la misma manera que, aunque sea mala comparación, decimos, muerto el perro, se acabó la rabia. Los que sabían que la locura y las graciosas extravagancias de don Quijote eran la causa de que Cide Hamete Benengeli, el cronista árabe a cuyos oídos llegaron, las pusiera por escrito, y de que Miguel de Cervantes las mandara traducir, los que sabían esto, es posible que pensaran que, muerto don Quijote, todo había concluido. Pero no fue así, porque las historias responden al conocido símil del cesto de las cerezas, las cuales, cuando alguien quiere sacar una, se eslabonan, hasta arrastrar a todas las demás, no sólo de ese cesto, sino del mismo mundo de los cerezos, y de ese modo, tras la historia de don Quijote, estaba esperando la historia de Sancho Panza, y con la suya, la de Teresa Panza y la de sus dos hijos, Teresica y Sanchico, y la del cura don Pedro, y la de maese Nicolás, y la de Sansón Carrasco, y la de la sobrina y la del ama del hidalgo, y todas las historias de aquellos que en algún momento tuvieron que ver con el caballero, la historia, por ejemplo, tanto más increíble, tanto o más aventurera que la del propio don Quijote, de Ginés de Pasamonte, el canalla galeote a quien liberó aquél y que no estaba resignado a desaparecer de la vida de Cervantes, o la del noble bandido Roque Guinard, que agasajó al caballero manchego en su manida, o la de Cardenio, conocido como El Roto o enamorado, o la de la dulce Dorotea, que el azar llevó a las profundidades de Sierra Morena, o las de la hermosa Luscinda y don Fernando, [...] o la novela de don Álvaro de Tarfe, que creyó que don Quijote era quien no era, y que luego se enmendó sin que le dolieran prendas en cuanto lo vio, o la historia de la pobre Dulcinea.... La dulce, la triste, la abandonada Dulcinea, que tanto llegó a odiar a don Quijote, la trágica y un poco cómica historia de Dulcinea. ${ }^{14}$

Larga reflexión aunque palmaria, aclaratoria y concluyente que va a ser completada por el párrafo que la continúa que no deja lugar a dudas del propósito de la empresa que el narrador acometerá en la historia y los capítulos que se seguirán: «De modo que la historia de don Quijote, el mismo día que murió, despertó, a cada cual más admirable, otras cien historias que estaban a su lado haciendo la guarda para ser

12 Marino Pérez-Álvarez, "Psicología del Quijote”, Psicothema, 2005, vol. 17, nº 2, p. 304.

13 C. Sigüenza, "Andrés Trapiello se alza con el premio Fundación Lara de novela", Diario de León, 8 de abril de 2005). Consulta digital en http://www.diariodeleon.es/noticias/noticia.asp?pkid=190939. [Última revisión septiembre de 2011].

14 A. Trapiello, op. cit., p. 24-25. 
contadas, y que de no haber sido por don Quijote habrían permanecido eternamente en su limbo» ${ }^{15}$.

Las vidas, los pensamientos, las actitudes, los miedos o las nuevas acciones de los personajes que rodearon a don Quijote en sus gestas e infortunios serán los principales focos de atención de Trapiello en esta novela. El autor leonés recuperará, se apropiará y recreará, desde su imaginación, los sueños, aspiraciones, nuevas aventuras y reveses de aquellas entrañables figuras modeladas por Cervantes hace cuatro siglos. Trapiello rescata de la narrativa cervantina las figuras de Sansón Carrasco, Sancho Panza, Antonia Quijano, la sobrina de don Quijote, Juan Cebadón y Quiteria, figuras del gañán y el ama a las que Trapiello pondrá el nombre que no quiso personalizar Cervantes. Junto a ellos deambularán entre las páginas del relato el cura, maese Nicolás, los duques que en la segunda parte del Quijote dan apariencia de realidad a las fantasías librescas del hidalgo caballero, Ginés de Pasamonte, Dulcinea y nuevos personajes como los de la familia de Cervantes, el propio Cervantes, el conde al que sirve Sansón Carrasco, Matías Barrientos, el gañán que sustituye al sirviente de la casa de don Quijote..., si bien, la trama narrativa recaerá sobre cuatro figuras: Sansón Carrasco, Sancho Panza, Quiteria y Antonia.

Como primer eslabón intertextual en las recurrencias de Trapiello con respecto a la novela de Cervantes es significativo el interés que tiene el autor por describir a los personajes y por las técnicas descriptivas en general, aunque en la novela matriz ya Cervantes abocetase los componentes descriptivos que más le interesaban para la conformación de su universo narrativo. A pesar de que Cervantes ya describiera y retratara con profusión y ejemplariedad el alma, el carácter o la apariencia de sus personajes y de que se extendiera en la descripción de lugares y espacios por los que deambularon sus figuras de ficción ${ }^{16}$, Trapiello gusta de la estrategia discursiva que ofrece la descripción para recrear los escenarios, espacios, topografía, fenómenos naturales y condiciones climáticas que enmarcan la acción complaciéndose en matizar las figuras de los personajes desde los distintos planos que plantean los cánones teóricos sobre el arte descriptivo.

Con respecto a los primeros describe la casa de don Quijote, el pueblo, las distintas condiciones climáticas, algunas estancias o el propio paisaje manchego, etc. Pero, sin duda, la descripción de los personajes ya desde los rasgos prosopográficos

15 Ibídem, p. 26.

16 A. Carreño, "Cartografía de los espacios: la casa en Don Quijote”, Actas del V Congreso internacional de la asociación de cervantistas. Lisboa: Asociación de Cervantistas, 2004, pp. 1200-1221; I. Lerner, “Tiempos y espacios en el Quijote", Voz y letra: Revista de literatura, Vol. 16, № 1-2, 2005 (Ejemplar dedicado a: el Quijote) , pp. 81-94; M. R. Cozzani de Palmada, C. Quintá de Kaúl, M. B. Badui de Zogbi, María Banura, A. García de Yaciófano, El espacio y el tiempo del Quijote, Mendoza, Ediunc, 2003. 
que los definen, ya desde los caracteres etopéyicos que los caracterizan tras el discurrir del tiempo, son esenciales en la configuración de la novela, así como en el conjunto de estrategias discursivas sobre las que se sustenta la misma.

Ama, sobrina, Sansón, Dulcinea, duques, Quijote, Ginés de Pasamonte, cura, maese Nicolás... van a volver a ser retratados con profusión y detenimiento de tal manera que fisonomía, apariencia, vestuario y rasgos más característicos de su personalidad volverán a ser objeto de atención. Trapiello vendrá a modelar la imagen completa de unos personas que ya describiera y retratara Cervantes para que el lector quiera volver sobre ellos. Véase como ejemplo el retrato que se ofrece de la sobrina de don Quijote:

A propósito de Antonia es extraño que Cide Hamete no descubriera nada de su belleza, cosa más extraña todavía en quien jamás solía pasar por alto esos detalles en las mujeres jóvenes y hermosas como la sobrina, que lo era en grado sumo.

Era más bien menudita y delgada, pese a lo cual le gustaba poner un cuerpo bajo, porque de ese modo sus camisas blancas realzaban un escote muy ponderado por las miradas de los hombres que pasaban por casa.

Tenía en el rostro tres lunares, uno sobre el labio, otro en la mejilla y otro en la sien, y sus labios finos y rosados se plegaban en un rictus de tristeza que humanizaban algo unos ojos de color miel, que podían hablar solos, si se lo proponían. Los ojos eran bellísimos desde luego, pero no lo serían tanto sin aquella boca que se desbordaba a menudo en ingenuas invitaciones y sonrisas, maliciosas e irresistibles, cuando no estaba enfadada por algo. ${ }^{17}$

Incluso en un habilidoso juego metanarrativo de ascendencia quijotesca empleado por Cervantes en la segunda parte de su obra ${ }^{18}$, los propios personajes, conocedores de que son protagonistas de ficción, advierten en el propio cuerpo de la novela sobre lo que puedan decir, hacer o acometer porque, sabedores de que sus acciones serán posteriormente plasmadas en letras de molde, tratarán de actuar de la mejor manera para que el novelista pueda retratarlos y describir sus acciones, sus figuras y sus juicios con la mejor de las suertes posibles:

Tanto como a vuestras mercedes, me preocupa a mí lo que se diga de nosotros el día de mañana. Y aun está el rabo por desollar y hasta el rabo todo es toro, y no tardando mucho, antes pronto que tarde, vamos a ver impresas las últimas y nuevas andanzas de don Quijote, todas las que se corresponden a estos últimos tres meses, desde que salió en junio hasta que lo traje hace quince días rendido desde Barcelona, con el juramento de que aquí se recogería durante un año. Y no me digan cómo, ni yo quiero saberlo, pero hasta estas mismas palabras que ahora estoy diciendo llegarán a la estampa y se darán a conocer, como se conocieron las otras, y tan por lo menudo que es mejor no meneallo. No sé quién será esta vez el historiador, el rabino Muscardino o don Lope de Vega. No sé vuestras

17 A. Trapiello, op. cit., p. 50.

18 A. Porqueras Mayo, Estudios sobre Cervantes y la Edad de Oro, Madrid, Centro de Estudios Cervantinos, 2003, pp. 127-136. 
mercedes, pero yo, pudiendo, me resisto a quedar en esta crónica como un necio, no siéndolo, o como culpable de haber robado al mundo, como insinúan ahora vuestras mercedes, uno de los siete sabios de Grecia o el dechado de todos los eremitorios de Egipto. Así que pongamos atención en lo que decimos y hacemos, porque de todo lo hablado aquí se está ya registrando, punto por punto, como hacen los imagineros, o mejor dicho, sin faltar coma, y yo defenderé aquí y en el día del Juicio lo que hice, como lo único y mejor que cabía hacer. ${ }^{19}$

Esta nueva entrega novelesca dentro de la colección de textos de ficción que pretenden continuar las aventuras de algunos de los protagonistas de don Quijote basa principalmente su acción en torno a cuatro personajes: Antonia, Quiteria, Sancho Panza y Sansón Carrasco, aunque la figura sobre la que gravita toda la trama y sobre la que se mueven el resto de deuteragonistas es la de Sansón Carrasco.

Es significativo que sea Sansón Carrasco, un personaje que no aparece hasta la segunda parte del Quijote aunque como ha sido reseñado se erija en protagonista principal de la historia y guía del destino de Alonso Quijano ${ }^{20}$, quien se erija en figura capital de la trama. Él es quien atrae a los demás protagonistas y quien mueve los hilos de acción del resto de antagonistas amén de ser el elegido por Trapiello para secuenciar las acciones de los demás personajes.

A la edad de veinticuatro años al morir don Quijote, Sansón Carrasco no «era muy grande de cuerpo, aunque sí de talle rocoso, de piel oscura y muy buen entendimiento. $\mathrm{Su}$ aspecto era característico, de nariz chata, boca abultada y ojos pequeños y vivos, señales de que era condición maliciosa, tracista y amigo de burlas» ${ }^{21}$.

Este personaje ira adquiriendo mayor protagonismo conforme avance la acción narrativa hasta capitalizar el desarrollo de la misma. Como el resto de los personajes, Sansón quiere buscar su propio destino al margen de lo que fue su relación con el hidalgo castellano. Por ello, como el bachiller cervantino se mostrará como un personaje inquieto, diligente, resuelto y activo cuya aspiración no será otra que la de poner por escrito algunos otros episodios quijotescos no relatados por don Quijote y, cual Trapiello y como Cervantes ya había hecho, relatar las historias de sus propios coprotagonistas: «Y acaso me anime yo a contar la historia de lo que sucedió, muerto

\footnotetext{
19 A. Trapiello, op. cit., 75-76.

20 «[Sansón Carrasco] es clave en la andadura novelesca [del Quijote] y se puede afirmar, con absoluta certeza, que mediante su figura puede reconstruirse todo el mundo quijotesco de 1615 . Sus intervenciones son claves en el andar quijotesco y constituye, junto a Dulcinea, el verdadero motor de la acción». E. Godoy Gallardo, "Presencia y sentido de Sansón Carrasco", Revista chilena de literatura, Noviembre 2005, Número 67, p. 66. Véase también C. Romero Muñoz, "La invención de Sansón Carrasco", en Actas II Coloquio Internacional de Cervantistas, Barcelona, Anthropos 1991, pp. 27-69.
}

21 A. Trapiello, op. cit., p. 52. 
él, a todos nosotros, antes de que cubran nuestros despojos las leyes del olvido» ${ }^{22}$. Hasta lograr su objetivo no habrá nada que lo detenga. Por una parte, el bachiller abandonará sus estudios a causa de su empeño por dedicarse a los libros y la literatura y, por otro lado, tratará de hacer acopio de otras historias acaecidas al hidalgo que él vivió o que le contaron para continuar forjando la historia no contada de don Quijote así como las aventuras de todos aquellos que vivieron junto a él.

El embozado Caballero de la Blanca Luna cervantino será el vértice de las dos principales líneas narrativas que atraviesan la novela. Por un lado, protagoniza la trama amorosa que se teje en el relato ya que, sin que se haya percatado, Antonia, la sobrina de don Quijote, suspira desde hace tiempo por él. Por otro lado, el segundo núcleo argumental de la obra: la aspiración de Sancho Panza de aprender a leer para poder recordar a don Quijote gracias a la letra impresa, contará con Sansón Carrasco como aliado y actor central, erigiéndose en un personaje esencial que emerge como voz oculta tras la que se esconde el propio escritor. Frente al maltrato unamuniano de este personaje $\mathrm{e}^{23}$, ya que no olvidemos que fue el encargado de derrotar a don Quijote $\mathrm{y}$, por tanto, el responsable de privarnos de otras hazañas y aventuras de Alonso Quijano, Trapiello hace de él un protagonista que, frente a las funciones, intención y tratamiento confeccionado por Cervante ${ }^{24}$, descubrirá el espíritu de don Quijote, que reparará en lo que supuso su vida, que se mostrará arrepentido de haber cometido la afrenta de derrotarle y que tratará de resarcir su error con el elogio y abierta exposición de lo que fue y de lo que representó la figura del Caballero de la Triste Figura.

Sancho, el fiel escudero de don Quijote, prosigue con el proceso de quijotización que ya trazaba Cervantes en la segunda parte de su obra, aspecto que ya fuera advertido por la crítica ${ }^{25}$, lo que viene a manifestar el conocimiento que Trapiello tiene de la obra cervantina. En la novela de Trapiello ya no hay ningún rasgo de la rudeza, la imprudencia, la vulgaridad, la incultura, la cobardía o la rusticidad de Sancho, la «quijotización» lo ha transformado de un rústico campesino al umbral de un hombre juicioso y sensato; un labriego que, a través de la locura ajena, descubre su propia realidad y halla la verdad de un mundo en el que el más loco es el más cuerdo. Si Sansón Carrasco es capital para el desarrollo de la acción narrativa, Sancho Panza es el

\footnotetext{
22 A. Trapiello, op. cit., p. 186.

23 M. de Unamuno, Vida de Don Quijote y Sancho, Madrid, Espasa-Calpe, 1961.

${ }^{24}$ Federico Peltzer, “Un opositor ambiguo: Sansón Carrasco", Revista de Literaturas Modernas, no , 27, 1994, pp. 47-71.

25 Véase al respecto desde el trabajo clásico de S. de Madariaga, Guía del lector del "Quijote", ensayo psicológico, Madrid, Espasa-Calpe, 1926; al de E. Urbina, El sin par Sancho Panza: parodia y creación, Barcelona, Anthropos, 1991.
} 
personaje mejor trazado en su sicología, rasgos y circunstancias vitales tras la muerte de su señor.

Si ya estudiosos como Dámaso Alonso han señalado que Sancho es una genial creación cervantina en tanto en cuanto es un personaje que se va haciendo y perfilando a lo largo del relato experimentando una clara evolución ${ }^{26}$, Trapiello sabe captar ese sentido cervantino del personaje, lo que provoca que Sancho continúe siendo un protagonista narrativo que se sigue haciendo a sí mismo. Al lado de su descripción, aprovechando las imágenes cervantinas y comentarios sobre lo que supusieron sus salidas conforme a lo que en la primera de sus aventuras se narra, Sancho es presa de las dudas, de la tristeza y de la melancolía al fallecer su señor; emociones expresadas en términos que vienen a confirmar el cambio quijotesco del fiel escudero. ${ }^{27}$ Durante buena parte de la novela, Sancho andará desaparecido y no será hasta bien avanzada la misma - capítulo veintidós - cuando Trapiello dirija la mirada narrativa hacia él. Para el fiel escudero la vida no tiene sentido. Su existencia se desvanece porque no hay nada que pueda sustituir a don Quijote hasta que no llega a vislumbrar cuál podría ser su nuevo destino y el elemento que pueda reemplazar su vida pasada y su penoso estado presente. Envuelto en una densa melancolía, tristeza y un profundo abatimiento que, muy al contrario del personaje retratado por Cervantes, ofrecen una figura de Sancho introvertida y reflexiva, muy diferente a la presidiera las aventuras cervantinas, Sancho reclamará para sí y su mundo tres elementos: «Paz, silencio, estudio». Es decir, las circunstancias necesarias para aplicarse al aprendizaje de la lectura para que, por ésta, pudiera revivir y recordar las enseñanzas de don Quijote y sus aventuras junto a él, constituyentes que, según el propio personaje expone, son los únicos que pueden devolverle las ganas de vivir:

Ahora empiezo a ver lo que don Quijote fue para mí y para todos nosotros, lo veáis o no. Y quiero consagrar este tiempo no a solaz, como sé que andas diciendo por ahí, poniendo al mundo en contra mía. Yo ya no conozco el solaz, para mí se acabaron los largos sueños, yo vigilo, pienso y me quemo las cejas, y donde no lo espero, se andan mil pensamientos toda la noche arriba y abajo como un rebaño con sed. Nos morimos de un día para otro, la vida se va en un soplo, y no brillan las estrellas con tanto ruido como nosotros sin luz ninguna nos movemos por este mundo. Otros se marchan de morabitos a una ermita; [...] y otros, en fin, se salen de su patria por correr aventuras en pos de venturas dudosas y muy hinchadas

\footnotetext{
26 Dámaso Alonso, "Sancho-Quijote; Sancho-Sancho", en Del Siglo de Oro a este siglo de siglas, Madrid, Gredos, 1968, p. 10; Véase también, José María Arbizu, Sancho, primer intérprete de don Quijote, Salamanca, Universidad Pontificia de Salamanca, 2001; Teresa Aveleyra, "Un hombre llamado Sancho Panza", Nueva Revista de Filología Hispánica, vol XXII, n. 1, 1973, pp. 1-16.

27 «Ven acá, Teresa. Dime: ¿Qué quedará de mí en este mundo? ¿Seré dueño de mi vida, dueño de mi fama? ¿Se habrá escrito todo lo que de mí convenía saber o me queda aún por vivir vida memorable? Mira que se muere don Quijote, ¿y qué será de mí? ¿Me espera nueva vida o habré de languidecer aquí esperando la muerte, contando mis aventuras con don Quijote, como soldado viejo? ¿Se acabó todo? Al morir don Quijote ¿no me he quedado a medio hacer? Yo antes no era así, a mí antes no me preocupaban estas cosas». A. Trapiello, op. cit., p. 56.
} 
ambiciones que nunca verán cumplidas. Don Quijote fue loco y yo soy cuerdo, y de eso va lo que de la noche al día. Pero el secreto de nuestro buen avenimiento estuvo en que yo llevé paciente su locura y él llevó con no menos paciencia $\mathrm{m}$ cordura, en lo que probamos los dos ser juiciosos. [...] Me lo has oído decir muchas veces, todos somos locos, los unos por los otros. Y ahora empiezo a comprender que el buen gobierno de una nación no lo hace un loco, pero tampoco un hombre en exceso juicioso, que a fuerza de buen juicio acabe en demasiado riguroso y soberbio, y así de éste redimiría su juicio un poco de locura, como le redime a don Quijote un poco, y aun un mucho de su cordura. Lo que pido ahora es bien poco. $\mathrm{Paz}$, silencio, estudio. ¿Es un delito que un hombre como yo quiera saber qué hizo para saber qué hará? ${ }^{28}$

Tras las enseñanzas de Sansón Carrasco, Sancho aprende a leer y, después de descubrir lo que la letra impresa dice de él y de que Trapiello siga mostrando y aderezando la evolución psicológica de un personaje, cada vez más sensato, discreto y consecuente con sus ideales, Sancho, al finalizar la obra, se muestra como otra persona, una figura activa, que ansía la libertad, que ha descubierto la verdad del alma quijotesca y que quiere continuar con la cruzada emprendida por su amo. ${ }^{29}$

Las dos mujeres protagonistas del texto de Trapiello, Antonia y Quiteria, figuras adyacentes en la trama del Quijote, siempre subordinadas a los dos protagonistas cervantinos, alcanzan aquí protagonismo más que significativo a pesar de ser curiosamente personajes antitéticos al universo vivido por Don Quijote y Sancho y de que Cervantes los silenciase y no las nominase. Sin llegar a estar completamente de acuerdo con el propio autor al reivindicar que «los grandes personajes de esta novela son las mujeres. Es una novela de mujeres ${ }^{30}$, como es «El Quijote» porque nadie como

28 A. Trapiello, op. cit., 254-255.

29 «Cuando empezó, el era uno, y vos y yo ya somos dos. No hay sino que salir mundo adelante, andar y ver, para darse cuenta de cómo van los famosos tuertos que decía mi amo, que con mirarlos muchos ya se enderezan de suyo, dando a entender con ello que si no lo habían hecho era por falta de cuidado y atención, y socorrer huérfanos, menesterosos, pobres, viudas, estropeados, doncellas desvalidas las más de las veces se consigue poniéndose uno a su lado, haciéndose ver, de la misma manera que no hay que hacer mucho en un gallinero sino estarse en él para que el raposo no lo avasalle, y estarse despierto junto al rebaño para que el lobo no se atreva a atacarle. [... ] Pues si es muy necesaria la locura para emprender según qué empresas, sólo puede coronárselas con un poco, y aun un mucho, de juicio. Al morir don Quijote yo era uno y hoy soy otro. Nunca pensé que algo así a un hombre barbado como yo pudiera ocurrirle. He visto mundo, me han manteado, apedreado, apaleado, robado y hambreado a lo largo y ancho de los caminos, pero fue libre. Mientras lo era, no supe que lo fui; murió mi amo, y con él mi libertad. En nuestro pueblo me ahogo y quiero alcanzar el colmo de los caminos, que es la libertad. Quiero a mi mujer y quiero a mis hijos, y dicen que el casado casa quiere, pero si me quedo con ella, me moriré como se murió don Quijote de melancolías. Quien conoció la libertad un día no puede ya vivir ni medio sin ella, y cuánto menos, toda una vida. Anímese, bachiller, vista sus armas y salgamos de nuevo al mundo». A. Trapiello, op. cit., p. 384.

30 Sobre esta cuestión véanse trabajos como los de Concha Espina, El amor de las estrellas. Las mujeres del Quijote, Editorial Renacimiento, 1916; Teresa Marín Eced, Figuras femeninas en el Quijote, Cuenca, Universidad de Castilla-La Mancha, 2007; Lidia Falcón, Amor, sexo y aventura en las mujeres del Quijote, Madrid, Ed. Vindicación Feminista 1997; Fanny Rubio, El Quijote en clave de mujeres, Madrid, Editorial Complutense, 2005; El Saffar, Ruth, "Elogio de lo que queda por decir. Reflexiones sobre las mujeres y su carencia en Don Quijote", Iris María Zavala, coord., Breve historia feminista de la literatura española, Vol. 
Cervantes quiso a las mujeres tan libres ${ }^{31}$; sí que funcionan como figuras importantes de esta novela aunque sin llegar a los extremos expresados por el autor si se comparan con los protagonistas masculinos antes analizados.

Quiteria, nombre asignado por Trapiello, a la innominada ama de la famosa novela cervantina, es un personaje que, por edad y madurez, encarna la sensatez, la prudencia, el buen hacer y el buen juicio. Trapiello desvela el inconfeso profundo amor que el ama profesaba hacia su dueño. Desde el primer encuentro, Quiteria queda enamorada del Caballero de la Triste Figura aunque, por prudencia, mantiene en secreto su amor durante todo su servicio. No será hasta la muerte de don Quijote cuando Quiteria se libere, no reprima más sus sentimientos y llore amargamente al ver yacer el gran amor por el que suspiraba en vida a pesar de los avatares y andanzas perpetradas contra él. A Quiteria se la retrata como una persona astuta e intuitiva, que vive y conoce los mecanismos que manejan el mundo real, honesta, limpia, leal, consejera y prudente y con orgullo que no se amilana ante nada y que sabe resolver los conflictos más arduos con sosiego, silencio y facilidad.

Sobre su figura se trama uno de las acontecimientos vertebrales relatados en la novela que abarca desde el capítulo quince, en el que se narra la particular historia de la entrada del ama al servicio de don Quijote, hasta el veintiuno, cuando, tras abandonar la hacienda de don Quijote, presa de la melancolía y del genio y soberbia de la sobrina y sin ningún asidero que la ate a la casa que sirvió durante veintisiete años, persuadida por Sansón Carrasco, vuelva al caserío manchego reclamada por la propia sobrina del andante caballero al verse y sentirse sola, desvalida, incapaz e indefensa ante unos aconteceres que comienzan a atormentarla y subyugarla.

En el resto de la novela, el ama, ocupará un papel secundario pero esencial en la historia de amor que protagonizarán Antonia y Sansón Carrasco al ser ella la encargada de allanar el camino y de limar cualquier escollo que pueda molestar al amor de los dos jóvenes deuteragonistas cervantinos que, en el relato de Trapiello, pasan a ser figuras protagonistas.

Antonia, la sobrina de don Quijote, será otro personaje cuyo carácter evolucionará a lo largo de la novela. Junto con el personaje de Sansón Carrasco, su vida deambulará por entre buena parte de las páginas de la novela erigiéndose en centro de la trama amorosa relatada en la misma. En las primeras escenas, muestra su gallardía, su orgullo, su coraje y su fortaleza al oponerse al escribano señor Alonso

II, Barcelona, Anthropos, 1995, pp. 291-326.

31 A. Serrato Martín, "Al morir Don Quijote", de Andrés Trapiello, obtiene el premio de la Fundación José Manuel Lara Hernández", Gibralfaro, núm 30. (Mayo 2005), p. 30. 
De Mal, quien pretende arrebatarle la hacienda familiar a no ser que Antonia acceda a casarse con él. Perdidamente enamorada de Sansón Carrasco desde hace tiempo, Antonia luchará contra De Mal para conservar sus bienes y patrimonio a pesar de los apremios de éste. Aunque sea presa de un desliz amoroso con el gañán de la hacienda, Juan Cebadón, Antonia se mantendrá firme en su resolución de esperar a Sansón Carrasco frente a las pretensiones de Alonso De Mal, quien promete darle todas sus riquezas si se desposa con él, y frente a los apremios de Juan Cebadón de proclamar su flaqueza y de haber deshonrado con su desliz sexual a la familia. Sola, desesperada, plena de remordimientos y acuciada por distintos personajes, Antonia recurre a Sansón Carrasco para que éste busque a Quiteria y, con ella, le puedan ser devueltos la paz, la armonía y el bienestar al hogar. Finalmente, apremiada por Sansón Carrasco, Quiteria perdona el orgullo de Antonia, lo que ocasionará la felicidad de la sobrina de don Quijote y que ésta cambie radicalmente su actitud y su comportamiento hacia el ama hasta el extremo de convertir a Quiteria en su mejor confidente y amiga y de que el ama, perdonadas las desatenciones pasadas, se afane en conseguir que Antonia logre despertar el amor en Sansón como se relatará en los últimos capítulos del libro.

Después de los breves comentarios ofrecidos sobre los personajes, se pone de manifiesto que el ser de los protagonistas, sus aspiraciones vitales y su retrato en las semanas que transcurren tras la muerte de Alonso Quijano, adquiere mayor relevancia que las posibles peripecias y aventuras postreras. Los episodios más significativos en lo tocante a la urdimbre novelesca se resumen en el desarrollo de la relación amorosa entre Antonia y Sansón Carrasco, estorbada por las pretensiones de Juan Cebadón y de Alonso De Mal, por el papel capital que adopte la figura de Sansón Carrasco como protagonista sobre quien gravite buena parte de la trama y por los deseos de Sancho por aprender a leer para, con ello, no olvidar ni la ilustre figura del caballero al que sirvió como escudero ni todo lo que vivió y aprendió junto a él, tramas aderezadas por breves interpolaciones de escenas o peripecias anecdóticas distanciadas de la trama principal.

\section{DiÁlogos, CORRESPONDENCIAS Y REFERENTES INTERTEXTUALES DESDE TrAPIELLO HACIA} SU FUENTE LITERARIA

En su deseo de rendir homenaje a la publicación de la primera parte del Quijote, don Quijote, personaje, y el propio libro de Cervantes serán constante objeto de atención, de comentario, de especulación, de exégesis y de acción en la novela de Andrés Trapiello.

Desde el cuidado por el lenguaje en ocasiones con aciertos y diáfanos fragmentos de marcado sabor y reminiscencias cervantinas hasta el tratamiento de los personajes 
pasando por las exégesis, reseñas e interpretaciones disgregadas a lo largo de la novela, uno de los valores y méritos virtuosos de la novela reside en que el escritor leonés no sólo ha sabido captar las esencias, sensibilidad y estilo del Quijote sino en haber plasmado, comentado e interpretado narrativamente algunos de los componentes del mismo y en haber hecho de la obra cervantina y de su personaje referentes textuales a pesar de la inercia de uno y de la muerte del otro aunque, como señala Antonia con respecto a su tío, pero cuyas palabras podrían extenderse a sus hazañas impresas en letras de molde: "Yo diría de mi tío lo que del Cid se dijo, que hasta muerto viene a ganar batallas, porque no se hace otra cosa, o a mí me lo parece, que hablar de él a todas horas». ${ }^{32}$

Tras comenzar un texto donde lo dejó otro autor, como ya hiciera Galdós en La desheredada $(1881)^{33}$, todo el armazón narrativo de la novela de Trapiello, así como las arterias que cohesionan la misma, se originan en las dos partes del Quijote y centrífugamente giran en torno a tres aspectos: 1) la figura de don Quijote, vista, recordada y comentada por los protagonistas o por el propio narrador; 2) la particular historia de la aparición y consecuencias del Quijote entendido como libro; $\mathrm{y}$, finalmente, la multitud de comentarios, teorías, anotaciones y explicaciones que sobre distintos aspectos compositivos, estilísticos, filosóficos, morales, literarios, culturales..., vierte Trapiello desde su conocimiento de la obra cervantina, desde su posición como crítico y ensayista y desde la condición comentador de los valores de la obra cervantesca.

Por encima de los propios personajes o de las tramas novelescas de esta obra, el libro, la historia del libro y los componentes, méritos o referentes más significativos del arte narrativo del Quijote serán motivos que se conviertan en constante objeto de atención en la novela de Trapiello, lo que hará que los incisos metanarrativos, las exégesis sobre la novela de Cervantes, los desvelamientos e interpretaciones sobre la ficción en la obra cervantina y las demás y continuas observaciones, razonamientos y comentarios autorreferenciales sobre la obra cervantina aparezcan constantemente como objeto de atención narrativa.

Trapiello incorpora como materia narrativa de Al morir don Quijote sus propias consideraciones sobre la novela, sobre don Quijote o sobre algunas de las teorías vertidas acerca de los más variados aspectos de la novela cervantina. Las dialécticas metaliterarias y juegos intertextuales se alzan como elementos que vehiculan la novela

\footnotetext{
32 A. Trapiello, op. cit., p. 179-180.

33 María del Prado Escobar Bonilla, "El legado de Cervantes: Presencia del Quijote en la narrativa galdosiana", Rafael Bonilla y Angelina Costa (Eds.), El Quijote (1065-2005), Córdoba, Universidad de Córdoba, 2006, p. 109.
} 
explorando buena parte de los méritos de la misma, por lo que el propósito inicial del escritor leonés se completa a través de un prisma panorámico en el que personajes y libro serán motivo de reflexión, de estudio, de comentario y de juego metaliterario sobre el que Andrés Trapiello desplegará un amplio abanico de perspectivas dimensionales siguiendo patrones heredados del texto que lo inspira.

Trapiello ofrece su particular teoría sobre la causa de la muerte de Alonso Quijano, -la melancolía-, como ya expusiera, entre otros, Fernando Rielo ${ }^{34}$. Comenta las consideraciones que los personajes-protagonistas del Quijote tienen sobre su tratamiento en la novela de Cervantes ${ }^{35}$. Expresa cuáles son a su juicio los grandes aspectos que defendió don Quijote: la libertad, la defensa de unos ideales, el ansia de aventura, la búsqueda de la verdad, el deseo de enderezar entuertos $\mathrm{y}$, en definitiva, cual caballero andante de su tiempo, seguir los dictados de las órdenes de caballería en lo tocante a sus virtudes de hacer el bien y luchar contra la injusticia ${ }^{36}$. Vierte diversas consideraciones y meritorias exégesis sobre lo que simboliza el personaje de don Quijote. Se atiene al deseo cervantino de que don Quijote muera para que nadie lo resucite ni pueda volver a imprimirse inacabables historias de sus hazañas. ${ }^{37}$ Saca a la luz los sentimientos encontrados o contradictorios que don Quijote despertaba

\footnotetext{
34 F. Rielo, Teoría del Quijote, Madrid, Ediciones Porrúa, 1982, p. 167.

35 «- ¿Y ha dicho vuestra merced que todo lo que hablemos aquí, saldrá algún día en letra impresa? -preguntó, el curo, que parecía haberse quedado en ese paso de su alegato, con la pluma en ristre y la mirada suspensa y los ojos, tras los cristales estrellados, vagamente soñadores-. ¿Va a decirnos que
} contamos entre nosotros con otacustas y delatores? [...]

En cambio aquella insinuación de que los presentes saldrían en los papeles les inquietó lo indecible, y se abrió allí un murmureo de conjeturas, discusiones y advertencias. Hubo quien, el barbero sin ir más lejos, vivió con ilusión esa posibilidad de saltar a la fama, sin necesidad de pasar por la locura de don Quijote, y empezó a maquinar en su interior las palabras que a partir de ese momento pronunciaría. Vio ámese Nicolás, y lo vio el cura, que lo que el bachiller decía tenía su lógica, y supusieron, por haber leído la primera parte de la historia, que la segunda no le iría a la zaga a la primera en cuanto a exactitud se refiere, y unos de una manera y otros de otra, todos se atusaron el pelo y se retocaron el vestido para quedar en una pintura.

Otros en cambio, como Sancho, que ya estaba de por sí muy confuso y harto inquieto con la fama, miraron esa posibilidad llenos de miedo, recelo y franca hostilidad». A. Trapiello, op. cit., p. 78-79.

36 Sobre este tema se remite al trabajo de Antonio Garrido Domínguez, Aspectos de la novela en Cervantes, Alcalá de Henares, Centro de Estudios Cervantinos, 2007, pp. 131-168; José Montero Reguera, El Quijote y la crítica contemporánea, Alcalá de Henares, Centro de Estudios Cervantinos, 1997.

37 Compárese el siguiente parágrafo: «Cuando se dieron por concluidas las obsequias fúnebres de don Quijote, insistió de nuevo el cura con el escribano, señor De Mal, para que dejara constancia de que metían en tan angosto y profundo agujero al mismo caballero que había salido a la luz en letras de molde como don Quijote de la Mancha, con el fin de que nadie viniera a aquella sepultura a remover sus huesos con nuevas honras ni aventuras impresas». A. Trapiello, op. cit., p. 87, con la sentencia que pone fin a la segunda parte del Quijote: «A quien advertirás, si acaso llegas a conocerle, que deje reposar en la sepultura los cansados y ya podridos huesos de don Quijote, y no le quiera llevar, contra todos los fueros de la muerte, a Castilla la Vieja, haciéndole salir de la fuesa donde real y verdaderamente yace tendido de largo a largo, imposibilitado de hacer tercera jornada y salida nueva; que para hacer burla de tantas como hicieron tantos andantes caballeros, bastan las dos que él hizo, tan a gusto y beneplácito de las gentes a cuya noticia llegaron, así en estos como en los estraños reinos». M. de Cervantes, Don Quijote de la Mancha II, Madrid, Cátedra, 1988, p. 578. 
entre las gentes o entre sus vecinos y amigos. Abunda en torno a la dialéctica entre la locura/cordura de don Quijote con teorías y explicaciones variadas hasta el punto de que los personajes que rieron sus andanzas se arrepientan de no haber sido capaces de ver el verdadero espíritu del caballero don Quijote:

Y si es cierto que las locuras de nuestro amigo mueven a risa todavía hoy, a mí han dejado de hacerme gracia, porque veo lo mucho que incomprendimos a don Quijote los que más decíamos comprenderle, porque sus locuras, siéndolo en la forma, nunca lo fueron en el fondo. Y sí, ahora me doy cuenta de qué equivocado andaba yo queriendo traerlo a casa, con la excusa de apartarlo de las burlas y los agravios que se le hacían en el ejercicio que él llevaba de deshacerlos en otros. ¡Qué necio fui queriéndolo reducir a mi cordura! El loco fui yo y todos cuantos creen que los libros son cosa diferente de la vida, que se leen y se olvidan! Para él cada libro fue un sol o una luna, que le daba o le quitaban luz, y yo le dejé a oscuras para siempre. ¡Yo sí que fui tonto, por pensar que las burlas menoscaban el honor de nadie, cuando suele ser lo contrario, que quien se burla de alguien suele quedar en esa burla a la postre peor que el burlado! Mi propósito, al querer vencer a don Quijote, fue, como quien dice, humano. El de don Quijote, al querer vencer a los gigantes, sobre humano y propio de un héroe. Yo me fingí caballero andante, y en eso anduve como impostor. Don Quijote no necesitó fingir con nadie, porque lo era, lo fue siempre a conciencia, sin engaño. Y por mucho que lo escarnecieran, apalearan y burlaran, y en el libro se ve, jamás le alcanzaron el corazón, que obraba tan rectamente humillando al soberbio y ensalzando al humilde, que es la única enseña que ha de seguir un hombre bien, y no al revés, como suele hacerse. Decir viva quien vence. ${ }^{38}$

Junto a los rasgos y parámetros explicitados, otro de los méritos constructivos de este texto son los hábiles juegos metaliterarios y las intertextualidades que el libro de Trapiello mantiene con el texto cervantino y con el propio cuerpo narrativo de la novela. El escritor leonés establece un hábil juego entre la realidad y la ficción, entre el personaje cervantino y el personaje trapiellano, mediante un doble uso de éstos. El personaje se siente vivo y real en manos de Trapiello, mientras que se ve retratado en el libro protagonizado por don Quijote y por ellos mismos, por lo que los protagonistas no sólo se saben personajes de ficción que pasarán a la historia por estar retratados en el más grande libro publicado y gozarán de la fama y la inmortalidad que la letra impresa les proporciona, sino que tratarán por todos los medios de llamar la atención y sobreactuar para aparecer en la segunda parte del Quijote que todos esperan o para que el lector pueda tener una imagen más real, completa y adecuada del personaje:

- No es cosa de brujería -protestó el bachiller-. Ya han visto cómo han salido vuestras mercedes con pelos y señales en la primera parte de esta historia. Se diría que llevaron pegado a los talones una espía de cámara, y hasta yo mismo hubiera figurado en esa crónica de haberme encontrado el año pasado en el pueblo cuando hizo don Quijote su primera salida. Si no me hubiese hallado en Salamanca haciéndome ostiario y exorcista, ahí figuraría mi nombre en letra impresa. ¡Y qué tendrá la letra impresa que a todos subyuga como la luna llena! Y del mismo modo

38 A. Trapiello, op. cit., p. 349-350. 
que se ha publicado esa primera parte, habrá una segunda. De eso no les queda la menor duda. En ella se relatarán todas las cosas que al loco de don Quijote y al no menos loco de Sancho, y sabes Sancho que lo digo sin ánimo de ofender, les han sucedido estos últimos tres meses, y en la que se asiente en libro todo esto mismo que ahora está teniendo lugar. ${ }^{39}$

No deja Andrés Trapiello de reflexionar sobre la personalidad, el carácter y las verdades de Alonso Quijano frente a don Quijote. ${ }^{40}$ Le seduce ofrecer la figura de don Quijote como el centro y el alma de la narración cervantina sin cuya presencia los personajes son huérfanos y seres sin destino. Trata de discernir acerca de lo que era realidad y ficción para don Quijote y aquello que es realidad y ficción en la vida real a través de comentarios relacionados con las ciencias filosóficas, la literatura, y las dialécticas propiamente literarias entre hechos reales y hechos recreados, entre lo real y lo imaginado. ${ }^{41}$ Ofrece a los personajes una oportunidad para arrepentirse ante el lector de algunos hechos realizados y de actitudes pasadas hacia el héroe cervantino. $\mathrm{Y}$, a la vez, pretende con su novela realizar una defensa firme y decidida del Quijote como obra maestra, elogiando la conmemorada primera parte del mismo: «Te llevas, Sancho, no un libro, no una historia, sino una reliquia, el crisol de todas las maravillas, el lucero de donde nace, como huracán, la aurora de estos tiempos modernos». ${ }^{42}$

\footnotetext{
39 Ibídem, p. 80.

40 «Pero me temo que nos ha dado que pensar mucho más el don Quijote loco que el Quijano cuerdo, y dijo aquél cosas más juiciosas y verdaderas en año y medio de loco, que en todos los que había vivido cuerdo entre nosotros, antes de que le diera por las andanzas caballerescas, pues les recuerdo a todos, y lo saben vuestras mercedes tan bien como yo, que don Quijote, que fue de natural melancólico, era además, antes de abismarse, un hombre taciturno y de poquísimas palabras, que costaba arrancarle. Fue enloquecer, y descoserse a hablar como no lo había hecho nunca, y con más coraje se entregó a su ideal estando loco, que estando cuerdo, si acaso ese ideal suyo de reparar los tuertos de la vida sólo parece posible tenerlo si se está un poco loco. Y hemos de reconocer que él ganó lo que buscaba, que fue nombre y fama en este mundo y gloria por sus buenas acciones en el otro. En aquél habrá de rendir cuentas no de sus obras, de las que no pueden pedírselas, por haberlas hecho encadenado a la locura, sino de la rectitud de su corazón. [...] Nos hemos dejado engañar, señores, por las apariencias, y si don Quijote por fuera, con aquellas trazas que llevaba, era un loco de remate, bastaba que se le plantearan cuestiones peliagudas, para que partiera el campo como no lo habría hecho ni el mismo Salomón, y tonto hubiera sido quien le metiera el dedo en la boca». A. Trapiello, op. cit., p. 74-75.
}

41 «[...] no estaría de más que vuesa merced, señor bachiller, fuese preparándole el terreno y advirtiéndole y enseñándole que una cosa es lo que se pone en los libros y otra muy diferente la realidad y la vida, y que en los libros se toman los historiadores licencias que no se corresponden punto por punto con las cosas que hemos vivido, y que eso las personas que tienen el hábito de leer lo saben y no les importa encontrárselas descomunadas y descomunales, porque ellos las vuelven con su buen juicio a las proporciones humanas; y aunque leamos en autores divinos como Homero que Diomedes partía de un solo tajo el cuerpo de sus enemigos, o que Aquiles se ventilaba en un santiamén veinticinco troyanos a los que ensartaba con su lanza como si fuesen magras, sabemos que ésas son licencias para darnos a entender su extremo valor y la inconmensurable fuerza de su brazo. Y así habrá de sopesar Sancho, cuando leyere su historia, en su justo término lo que fueron los hechos y lo que puso el autor, para salpimentarlos, con las especias que le dan sabor, pero que no añaden un átomo de sustancia ni alimento a las presas, a saber, la hipérbole, el retruécano, la metáfora y todas las que podríamos considerar las alcamonias de la gramática, porque a menudo, sin ese arte coquinario, la realidad no se puede tragar». A. Trapiello, op. cit., p. 269-270.

${ }^{42}$ Ibídem, p. 323. 
Los recursos metanarrativos e intertextualidades relacionadas con el texto cervantino se completan con interesantes comentarios sobre lo que supone la lectura y los libros para los seres humanos ${ }^{43}$; constantes observaciones acerca del mantenimiento oculto de la identidad del pueblo de don Quijote; anotaciones sobre el Quijote de Avellaneda; pasajes donde la edición de la primera parte del libro o la esperada segunda parte son objeto de atención y comentario; o con recolecciones y apropiaciones de escenas y palabras del texto original que son insertadas y mezcladas con nuevas peripecias y con pasajes sobre la historia del libro cervantino, los avatares de la novela desde su publicación o los plagios e intentos de aprovechamiento de personajes e historias del Quijote como el realizado por Avellaneda:

Las dirigía a don Fernando, a Luscinda, a Cardenio, a don Ruiz Pérez de Biedma y a su hermano don Juan, que habían conocido a don Quijote y simpatizado con él, admirándose de su estampa y su discurso, y a los que maese Nicolás y él mismo, el cura, habían conocido cuando salieron a buscar a su vecino y amigo. Todos ellos, al despedirse cuando enjaularon a don Quijote para traérselo consigo, le habían rogado que les escribiera contándoles en qué paraban aquellas prisiones del caballero de la Triste Figura y aquel suceso. [...] y recomendaba don Pedro a todos aquellos correspondientes el libro que recogía la puntual y todavía parcial crónica de las cosas sucedidas a don Quijote, anunciándoles que también formaban parte ellos de ella, aunque les advertía que si lo adquirían, advirtieran que se trataba del de Miguel de Cervantes y no uno que circulaba con embustes afrentosos y vulgares, bajo la férula de un tal Avellaneda $[. . .]^{44}$.

\section{CONCLUSIón}

En conclusión, Andrés Trapiello plantea como punto de inicio de su contribución y homenaje al año centenario de la publicación de la primera parte de El ingenioso hidalgo don Quijote de la Mancha la recreación de las historias presentes y nuevas peripecias novelescas de los deuteragonistas del Quijote con el ánimo de descubrir qué fue de sus vidas al morir el ilustre hidalgo. Sin embargo, el proceso narrativo va a ocasionar que la vida de los personajes se vea superada por la atención al objeto del que partieron, el libro de Cervantes, y por las continuas digresiones y exégesis metanarrativas acerca

43 «Dejemos a un lado tales consideraciones, porque el mal no estaba en los libros, sino en la cabeza de aquel hombre bonísimo que conoció la gracia de volver a su cordura. No son nocivas las cosas, sino lo que con ellas pueda hacerse, [...] Y así los libros, siendo nocivos, serán inocuos a los ojos de quien los lea, si éste es alguien discreto y de buenas luces. [...] Entre los libros que uno encuentra deleznables, puede hallar otros tesoros escondidos, y en las bellezas que se le muestran a uno, no hallar otro más que escoria. [...] Y no hay libro, por malo que sea, que pasados unos años no se muestre mejor de lo que era, y si se muestra peor lo hace sin su penoso rostro, como veneno que ha perdido sus poderes. [...] Sé por experiencia que el libro que hoy te pareció bueno, entretenido y provechoso, leído al cabo del tiempo lo encuentra uno tedioso y desustanciado, y el que, por el contrario, reputó uno como hijo de un ingenio harto fatigado, lo halla, al cabo de los años, lleno de inauditas novedades. Y muy raro es aquel alimento que aprovechándote de joven, te deleite de viejo, que a todo acaba perdiéndosele el gusto, como no sean los manjares de los dioses, el maná del cielo y la ambrosía». A. Trapiello, op. cit., p. 289.

44 A. Trapiello, op. cit., p. 73-74. 
del propio libro y de las claves internas del mismo a través de una dialéctica en la que autor omnisciente, personajes de ficción y obra cervantina dialogan sobre algo que le es común: el Quijote, obra, y don Quijote, personaje, aspecto cuya importancia es capital para la estructura y armazón narrativo de la novela.

Partiendo del fondo literario del Quijote, Andrés Trapiello ofrece una novela que invita a la lectura del texto que la engendra y que, a su vez, ofrece un amplio muestrario y un fértil compendio de muchos de los comentarios, teorías y apreciaciones del autor continuador acerca del texto y del escritor que prolonga.

\section{Bibliografía}

ALONSO, D. "Sancho-Quijote; Sancho-Sancho", en Del Siglo de Oro a este siglo de Siglas, Madrid, Gredos, 1968, pp. 9-19.

CASTILLA, A., “Trapiello gana el Fundación Lara con Al morir don Quijote”, El País, 8 de abril de 2005.

CERVANTES, M. de, Don Quijote de la Mancha II, Madrid, Cátedra, 1988.

COTARELO Y MORI, E. "Otro imitador de Cervantes en el siglo XVIII" y "Las imitaciones castellanas del Quijote", en Estudios de historia literaria de España, I, Madrid, 1901.

ESCOBAR BONILLA, Ma . del P., “El legado de Cervantes: Presencia del Quijote en la narrativa galdosiana", Rafael Bonilla y Angelina Costa (Eds.), El Quijote (10652005), Córdoba, Universidad de Córdoba, 2006, pp. 103-120.

GODOY GALLARDO, E. "Presencia y sentido de Sansón Carrasco", Revista chilena de literatura, noviembre 2005, Número 67, pp. 53-67.

INTXAUSTI, A., “Andrés Trapiello se apropia de los personajes del Quijote e inventa sus vidas", El País, 14 de octubre 2004. Consulta digital en http://www. elpais.com/articulo/cultura/Andres/Trapiello/apropia/personajes/ Quijote/inventa/vidas/elpepicul/20041014elpepicul_7/Tes [Última consulta septiembre de 2011]

PÉREZ-ÁLVAREZ, M., “Psicología del Quijote”, Psicothema, 2005, vol. 17, n 2, p. 303310.

PORQUERAS MAYO, A., Estudios sobre Cervantes y la Edad de Oro, Madrid, Centro de Estudios Cervantinos, 2003.

RIELO, F., Teoría del Quijote, Madrid, Ediciones Porrúa, 1982.

RIQUER, M. de, Para leer a Cervantes, Barcelona, Acantilado, 2003.

SERRATO MARTÍN, A., "Al morir Don Quijote", de Andrés Trapiello, obtiene el premio de la Fundación José Manuel Lara Hernández", Gibralfaro, núm 30. (Mayo 2005). 
SIGÜENZA, C., "Andrés Trapiello se alza con el premio Fundación Lara de novela", Diario de León, 8 de abril de 2005). Consulta digital en http:/ / www.diariodeleon. es/noticias/noticia.asp?pkid=190939. [Última revisión septiembre de 2011].

TELLO, R., “El punto oscilante en Las tradiciones de A. Trapiello”, Poesía en el campus. Revista de poesía, n⿳3 37, 1996-1997, pp. 10-14.

TRAPIELLO, A., Al morir don Quijote, Barcelona, Ediciones Destino, 2004.

UNAMUNO, M. de, Vida de Don Quijote y Sancho, Madrid, Espasa-Calpe, 1961.

VILLANUEVA, D. "El Quijote desde la novela actual”, en I. Suárez Andrés et al. (Eds.), Huellas del Quijote en la narrativa española contemporánea, Actas de las Jornadas Hispánicas de Neuchâtel, 25-25 de noviembre de 1995, Universidad de Neuchâtel, 1996, pp. 13-31. 